\title{
Feasibility and Efficacy of Left Ventricular Lead Placement Guided by Subselection Inner Catheter Alone in Cardiac Resynchronization Therapy Device Implantation
}

\author{
Kazuto Hayasaka ${ }^{1}$, Takeshi Sasaki ${ }^{1}$, Ko Akimoto ${ }^{1}$, Kento Yabe ${ }^{1}$, Chisashi Toya ${ }^{1}$, Syu \\ Yamashita $^{1}$, masahito suzuki ${ }^{1}$, Koji Sugiyama ${ }^{1}$, Masahiko Goya ${ }^{2}$, and Tetsuo Sasano ${ }^{2}$ \\ ${ }^{1}$ National Disaster Medical Center \\ ${ }^{2}$ Tokyo Medical and Dental University
}

December 16, 2020

\begin{abstract}
Introduction: Subselection inner catheters (Inner-Cath) are used adjunctively with outer guiding catheters (Outer-Cath) during cardiac resynchronization therapy (CRT) device implantation. This study aims to investigate the feasibility and efficacy of left ventricular lead placement (LV-LP) guided by Inner-Cath alone. Methods: A total of 74 patients undergoing de novo CRT implantation were investigated. LV-LP was initially guided by Inner-Cath in 42 patients (Inner-Cath group) and Outer-Cath in 32 patients (Outer-Cath group). In the Inner-Cath group, a 7Fr Inner-Cath was advanced to the coronary sinus through a 7 Fr sheath inserted in a subclavian vein. In the Outer-Cath group , 9Fr or 10Fr Outer-Caths were used. Success rate of LV-LP, additional use of inner or outer catheters and procedure-related complications were compared between groups. Results: LV-LP was successful in all patients in the Inner-Cath group while LV-LP had to be abandoned in 2 patients of the Outer-Cath group due to CS perforation caused by Outer-Cath manipulation. Procedure time was significantly shorter in the Inner-Cath group (148 vs $168 \mathrm{~min} ; \mathrm{P}=0.024$ ). Deployment of both an inner and outer cath became necessary less frequently for the Inner-Cath group ( $4.8 \%$ vs $56.3 \% ; \mathrm{P}<0.001$ ). Mechanical CS injuries due to guiding catheter manipulation were only observed in the Outer-Cath group ( $0 \%$ vs $15.6 \%, \mathrm{P}=0.013$ ). Conclusion: LV-LP guided by Inner-Cath alone was feasible in over $95 \%$ of the patients without severe complications. This methodology for LV-LP may be preferable in CRT candidates with severe LV dysfunction in terms of shorter procedure time, smaller guiding sheath and less complications.
\end{abstract}

\section{Introduction}

Cardiac resynchronization therapy (CRT) has been shown to prevent hospitalizations for heart failure and improve mortality in patients with severe left ventricular (LV) dysfunction and inter-ventricular or intraventricular electromechanical dyssynchrony (1-8). However, LV lead placement (LV-LP) in the target branch of the coronary sinus (CS) tributaries can be difficult due to variations in coronary venous anatomy (9) despite the recent advances in delivery systems for LV-LP (10-14). This is one of the causes of non-response to CRT. In general, $9 \mathrm{Fr}$ or $10 \mathrm{Fr}$ outer guiding catheters (Outer-Cath) with a variety of curves and shapes are initially selected for CS cannulation to serve as backup force for LV lead delivery to a target vein. At other times, a subselection inner catheter (Inner-Cath) may be used adjunctively to guide the Outer-Cath into the CS more safely, especially in difficult cases of CS cannulations, which can lead to complications such as CS dissection or perforation $(15,16)$. However, efficacy and safety of the LV-LP using only the smaller 7Fr Inner-Cath for CRT implantation has never been investigated before. The aim of this study was to investigate the feasibility, efficacy, and safety of LV-LP guided only by an Inner-Cath as a first-line approach to CRT implantation.

\section{Methods}




\section{Study patients}

This study consisted of 74 consecutive patients who underwent de novo CRT implantation between January 2015 and July 2019. In addition, 8 patients with CRT upgrades from pacemaker or implantable cardioverter defibrillation (ICD) systems, which were guided by Inner-Cath only, were investigated. All patients received de novo CRT implantation or upgrade to CRT systems according to guideline indications (17) that included patients with NYHA classes II-III or IV despite optimal medical treatment, LV ejection fraction (LVEF) [?] 35\% and QRS duration [?]120ms, or LVEF <50\% and expected high frequency right ventricular (RV) pacing. The patients with de novo CRT implantation were divided into two groups based on the type of guiding catheter used initially for LV lead placement (LV-LP), namely, 7Fr Inner-Cath (Inner-Cath group, $\mathrm{N}=42$ ) and 9 or $10 \mathrm{Fr}$ Outer-Cath (Outer-Cath group, $\mathrm{N}=32$ ). Outer-cath was selected as a first-line method in the first 32 patients. Inner-cath was selected as a first-line method in the latter 42 patients. This study was a non-randomized retrospective observational study. The research protocol had been approved by the local Research Ethics Committee. Informed consent was obtained in the form of opt-out.

\section{CRT device implantation}

Device leads of the CRT system were inserted through sheaths placed in the right or left subclavian vein under fluoroscopy. Right ventricular and right atrial leads were fixed in the conventional positions inde-novo CRT implantations. An LV lead was selectively positioned in one of the CS tributaries. A pulse generator was implanted in the left or right precordial area. The CRT device implantation or upgrade procedures were performed under mild or moderate sedation with local and intravenous anesthetics.

\section{LV lead placement}

In the Inner-Cath group, a 7Fr Inner-Cath with 90 degree-angled tip was advanced to the CS trunk using a 5Fr EP-catheter (EP star, Japan Lifeline, JAPAN) or 3.5-inch guide wire through a 7 Fr short sheath placed in the left or right subclavian vein (Figure 1). A 5Fr EP catheter or 3.5-inch guide wire was inserted into the CS as deeply as possible to strengthen backup force for an Inner-Cath insertion into the CS without additional use of an Outer-Cath. Then a CS venogram was performed by injecting contrast medium through the Inner-Cath or a catheter with a balloon on its tip for occlusive venography if necessary. In cases where the Inner-Cath was directly cannulated into a CS tributary, selective venography through the Inner-Cath was possible (Figure 1). A 0.014-inch guide wire inserted within an LV lead was initially advanced to the target CS tributary under fluoroscopy. Then, an LV lead was advanced to the target vein along with the guide-wire alone. After confirming the LV lead had been steered into appropriate position, the Inner-Cath and 7Fr sheath were peeled off for removal. In cases of difficult CS cannulation with an Inner-Cath alone or difficult LV lead placement in a target vein, an Outer-Cath was additionally used. In the Outer-Cath group, a $9 \mathrm{Fr}$ or $10 \mathrm{Fr}$ Outer-Cath with different angles was advanced to the CS trunk through $9 \mathrm{Fr}$ or 10Fr sheaths placed in the subclavian vein using conventional methods. A CS venogram was performed using a balloon catheter and the LV lead was advanced to the target CS tributary. In cases of difficult CS cannulation with an Outer-Cath or difficult LV lead placement in the target CS tributary, an Inner-Cath was additionally used.

\section{Statistical data analysis}

The data are presented as mean \pm standard deviation or median [1st-3rd quartile] for continuous variables as appropriate, and as frequency (\%) for categorical variables. Variables were compared with Student's t-test or Mann-Whitney test. Categorical data were compared with the $\chi^{2}$ test or Fisher's exact test. All statistical analyses were performed with JMPß 14 (SAS Institute Inc., Cary, NC, USA). In all analyses, a two-tailed p-value $<0.05$ was considered to indicate statistical significance.

\section{Results}

\section{Patient characteristics}

Characteristics of Inner-Cath group $(\mathrm{N}=42)$ and Outer-Cath group $(\mathrm{N}=32)$ patients with de novo CRT 
implantation are shown in Table 1 . The patients of the Inner-Cath group were significantly younger $(63 \pm 12$ vs. $72 \pm 11$ years, $\mathrm{P}=0.015)$ and received a greater number of CRT defibrillators (CRTD) (95\% vs. $66 \%$, $\mathrm{p}<0.001)$ compared with the Outer-Cath group. Gender, comorbidities, and indicators of heart failure did not differ significantly between the two groups.

\section{LV lead placement Procedure Outcomes}

All 42 patients of the Inner-Cath group received successful LV-LPs. Forty of them (95.2\%) were guided by an Inner-Cath alone while the remaining 2 patients $(4.8 \%)$ required an additional use of an Outer-Cath (Table 2). Meanwhile, 30 of 32 patients (93.8\%) of the Outer-Cath group successfully received LV-LPs. In 2 patients $(6.2 \%)$ of the Outer-Cath group, the LV-LP had to be abandoned due to CS perforation during repeated cannulations of the Outer-Cath to the CS trunk. Total procedure time and time to LV-LP were shorter in the Inner-Cath group ( $148 \pm 38$ vs. $168 \pm 42 \mathrm{~min}, \mathrm{P}=0.024 ; 77 \pm 35$ vs. $96 \pm 36 \mathrm{~min}, \mathrm{P}=0.011$, respectively). No significant differences were observed in fluoroscopic time and dose, contrast dose, or incidence of LV lead dislodgements due to peeling-off of the guiding catheters. The additional use of an Outer-Cath or Inner-Cath was required less frequently in the Inner-Cath group than in the Outer-Cath group (4.8\% vs. $56.3 \%, \mathrm{P}<0.001)$. LV lead threshold was significantly lower in the Inner-Cath group $(0.9 \pm 0.5$ vs. $1.2 \pm 0.5$ $\mathrm{V}, \mathrm{P}=0.0498$ ). All LV leads were placed in the anterolateral, lateral and posterolateral LV areas without a significant difference in distribution of location between the 2 groups.

\section{Representative Cases}

Three representative cases of LV-LP guided by Inner-Cath alone are shown in Figure 2. LV leads were successfully placed in different CS tributaries (posterolateral, lateral, anterolateral veins). Case 1 was a 74 year-old male with dilated cardiomyopathy (DCM). It was possible to advance an Inner-Cath deeply inside a thick posterolateral vein, that strengthened the backup force for LV lead delivery into the target vein. Case 2 was a 75 -year-old male with ischemic cardiomyopathy (ICM). Although an Inner-Cath was only advanced to a proximal bend of the lateral vein, the LV lead was smoothly delivered to an adequate position. Case 3 was a 43-year-old male with ICM. The targeted anterolateral vein diverged from the CS trunk with a curve of greater than 90 degrees. Despite the Inner-Cath not being expected to provide enough backup force for LV lead delivery, the LV lead was successfully inserted into the targeted anterolateral vein without effort.

\section{Procedure-related Complications}

The incidence of procedure-related complications was observed more frequently in the Outer-Cath group (4.7 vs $31.3 \%$; $\mathrm{P}=0.002$, Table 3 ). A major cause of procedure-related complications was mechanical injury of the CS due to the repeat cannulations of the Outer-Cath into the CS, which was observed in 5 patients (15.6\%) of the Outer-Cath group. As a result of CS perforation, 2 patients required abandonment of the LV-LP. Figure 3 demonstrates a case with CS perforation due to repeated cannulations of an Outer-Cath into the CS trunk. However, LV-LP was finally achieved by using an Inner-Cath alone without any problems. In addition, LV lead dislodgement was observed in one patient (2.4\%) from the Outer-Cath group a month after the procedure.

\section{CRT Upgrade Procedures}

Eight patients successfully underwent CRT upgrade procedures guided by an Inner-Cath alone without any complications. Of all 8 patients receiving CRT upgrade, 5 patients $(62.5 \%)$ showed stenosis of the subclavian vein (4 patients) or both subclavian and brachiocephalic veins (1 patient) due to adhesions of pacemaker leads to the venous wall. Consequently, one of the 5 patients only required a dilation of the left subclavian vein for insertion of a $7 \mathrm{Fr}$ sheath into the stenotic vein. In another patient with left subclavian and brachiocephalic vein occlusions, a 7Fr sheath was successfully inserted through the occluded veins with angioplasty (Figure 4).

\section{Discussion}

Major findings 
To the best of our knowledge, this is the first study to investigate the feasibility and efficacy of LV-LP guided by Inner-Cath without Outer-Cath as a first-line methodology in CRT implantation. The study results demonstrated that LV-LP guided by Inner-Cath alone was successful in over $95 \%$ of the patients undergoing de novo or upgrade CRT implantation without severe complications. The Inner-Cath group had shorter total procedure time and less procedure-related complications. In particular, mechanical CS injury during CS cannulation caused by the guiding catheters was only observed in the Outer-Cath group. Consequently, we consider LV-LP guided by Inner-Cath alone to be safer and more effective compared with conventional methods that use Outer-Cath.

\section{Success rate of LV lead placement guided by Inner-Cath}

Recent progress in CRT implantation procedures including LV-LP has been made possible based on the improved design of guiding catheters and LV leads, and advanced techniques. In spite of these improvements, one still encounters difficult cases of LV-LP during CRT implantation due to reasons as described in previous reports $(9,18-20)$. Those reports showed that about $10 \%$ of patients with CRT implantation had unsuccessful LV-LP, which we believe is comparable to the $6.2 \%$ failure rate of the Outer-Cath group in the current study. Meanwhile, LV-LP guided by Inner-Cath alone or Inner-Cath with Outer-Cath was successful in all patients (100\%) in the present study. Surprisingly, $40(95.2 \%)$ of 42 patients had successful LV-LP guided by InnerCath alone, justifying the use of Inner-Cath as a first line methodology for LV-LP.

\section{Advantages of LV-LP guided by Inner-Cath}

LV-LP guided by Inner-Cath alone has some advantages leading to the high success rate of LV-LP. First, an Inner-Cath can be easily and safely cannulated into the CS regardless of various CS anatomies or size of right atrium (9), especially when using a 5Fr steerable EP catheter (11) as electrophysiologists are familiar with its manipulation. In fact, mechanical injuries of the CS such as dissection and perforation were more frequently observed in the Outer-Cath group. In addition, it is not difficult to advance an Inner-Cath deep inside the target CS tributaries, that may result in shortened procedure time and reduce radiation exposure compared with the Outer-Cath group. Our method makes it unnecessary to select from a variety of OuterCath with different shapes and curves. Given the excellent success rate of LV-LP guided by Inner-Cath alone, it appears that an Inner-Cath provides sufficient backup force to deliver LV leads to the target veins in spite of the varied anatomy of CS tributaries. Our results suggest that it is a misconception that use of an Outer-Cath is always necessary to get adequate backup force for LV lead delivery. Our study results also showed that LV threshold was significantly lower in the Inner-Cath group than that of the Outer-Cath group. We surmise that this was due to Inner-Cath superiority to Outer-Cath in terms of enabling selection of optimal CS tributary and LV lead placement site, especially in patients with ICM in whom the LV pacing may be affected by scar location (21). Second, peel-off of the Inner-Cath for removal from the CS may be easier than that of the Outer-Cath. We often experience LV lead dislodgement when peeling off the OuterCath, which is caused by a mismatch between the position of the CS ostium or CS trunk and shape of the selected Outer-Cath with different curves. Meanwhile, the LV lead is very unlikely to become dislodged during peel-off of an Inner-Cath because it has a simple shape without complex curves. Third, an Inner-Cath can be repeatedly inserted through a smaller 7 Fr sheath in the subclavian vein unlike the Outer-Cath that requires an $9 \mathrm{Fr}$ or $10 \mathrm{Fr}$ sheath. The use of a smaller sheath has substantial advantages in terms of avoiding the risk of unnecessary bleeding from the insertion site of the sheath and interference from other sheaths in manipulating a guiding catheter, especially in patients undergoing a CRT upgrade who may have subclavian vein stenosis due to the adhesion of previously inserted leads to a venous wall as shown in Figure 4.

\section{Additional use of Outer-Cath for LV-LP guided by Inner-Cath}

In the Inner-Cath group, most of the LV-LPs were successfully guided by Inner-Cath alone except for 2 patients, who required additional use of an Outer-Cath for CS cannulation of the guiding sheath due to marked enlargement of the right atrium. Preprocedural CT or MRI images may be useful to assess not only the anatomy of the CS trunk and tributaries but also those of both atria, predicting difficult cases of LV-LP guided by Inner-Cath alone. 


\section{Procedure-related Complication}

In general, procedure-related complications in CRT implantations are more frequently observed in female patients with CRT-D, mostly attributable to pneumothorax, pericardial tamponade, and CS dissection (15). The incidence rate of CS dissection has been reported as ranging from 1.4 to $6.8 \%(15,16)$, which may be caused by inadequate cannulation to a CS branch, presence of intravascular obstructions, aggressive manipulation of a guiding sheath, tortuous vessels, or unusual anatomy (16). In the current study, procedurerelated complications, especially mechanical injuries of the CS were significantly less in the Inner-Cath group. The use of Inner-Cath for CS cannulation, especially guided by an EP catheter, may prevent risk of mechanical injuries of the CS trunk and tributaries due to the manipulation of guiding catheters.

\section{Advantages of LV-LP guided by Inner-Cath in CRT upgrade}

In upgrading a pacemaker to a CRT device, severe stenosis or occlusion of the subclavian vein has been a critical problem, identified in from 13 to $35 \%$ of patients undergoing CRT upgrade (22). Venoplasty of the subclavian and/or brachiocephalic veins is one of the options for achieving LV-LP through the occluded or stenotic subclavian vein, but remains challenging (23). The smaller Inner-Cath is clearly superior to the larger Outer-Cath in terms of inserting a sheath through the occluded or stenotic subclavian veins.

\section{Limitations}

This study was a non-randomized retrospective observational study. Small sample size and inter-operator variability due to the skill of each operator may have affected the reliability of the study results. The measurement of RA size was not quantitatively assessed with CT or MRI images in all patients. All patients were Asian and differences in physique between races may affect applicability of our results to other races. There were differences in age and implanted devices between the 2 groups. However, we don't believe they contributed to the study results. Further prospective multicenter studies will be required to elucidate the safety and efficacy of LV-LP guided by Inner-Cath alone.

\section{Conclusion}

LV lead placement guided by Inner-Cath alone was successfully and safely performed in over $95 \%$ of the patients undergoing de-novo or CRT implantation upgrade. This methodology for LV lead placement with Inner-Cath alone may be preferable, especially in CRT candidates with severe LV dysfunction in terms of its shorter procedure time, smaller size of guiding sheath and fewer procedure-related complications.

Figure 1: LV lead placement guided by Inner-Cath alone

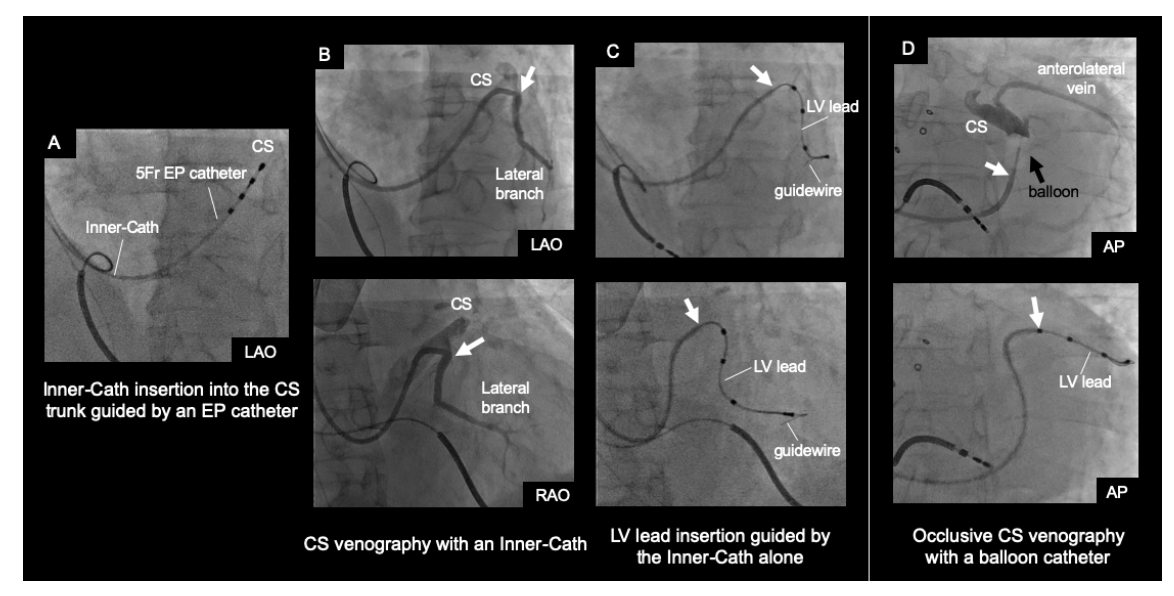

Figure 2: Representative cases with LV-LP guided by Inner-Cath alone 


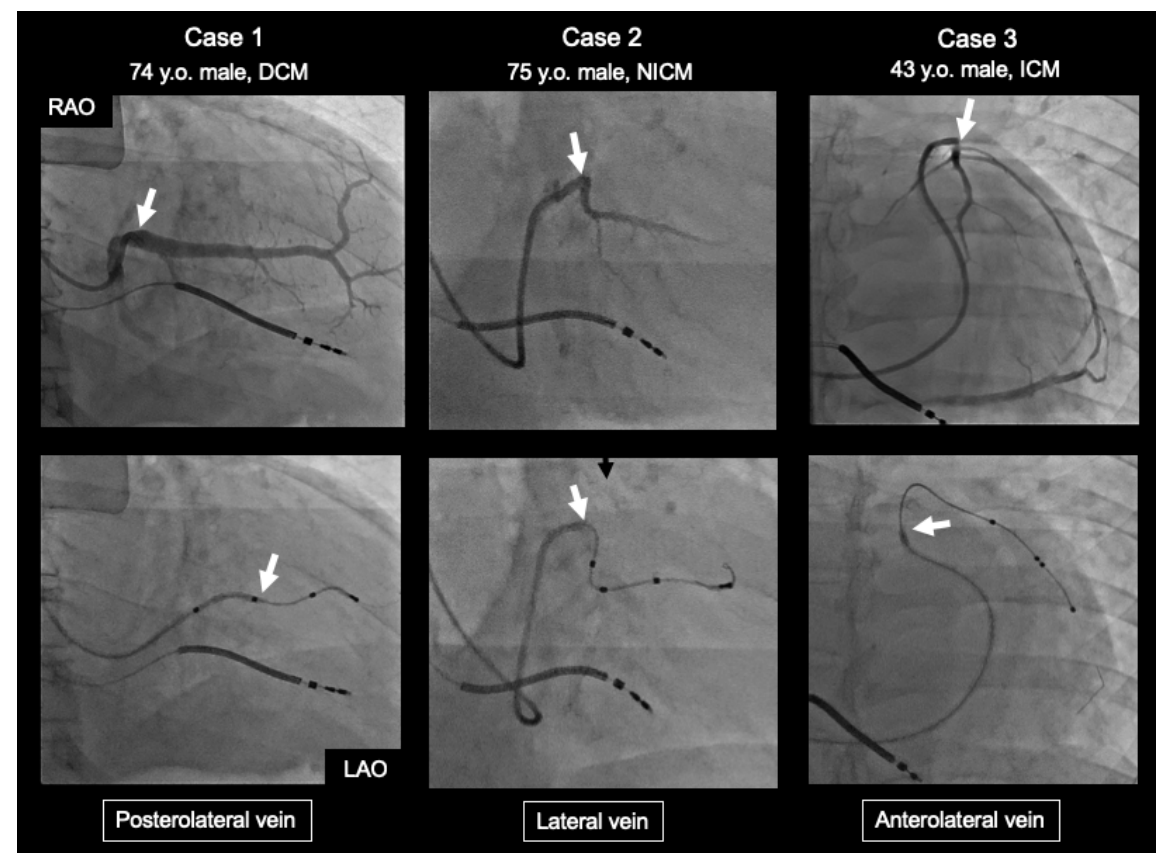

Figure 3. A case with CS perforation due to repeated CS cannulations with an Outer-Cath
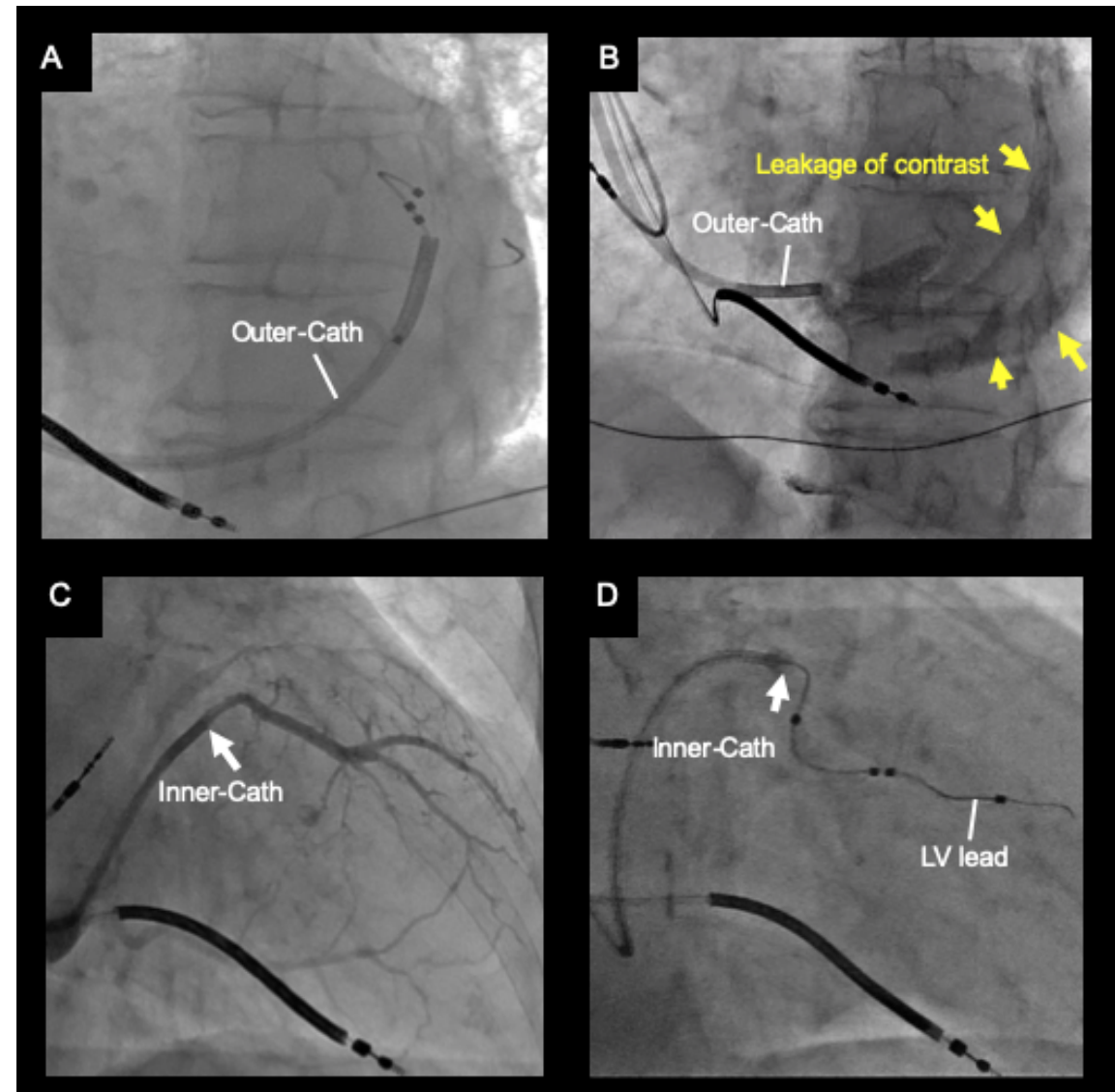
Figure 4. LV-LP guided by Inner-Cath alone after venoplasty in a case with occluded left brachiocephalic vein.

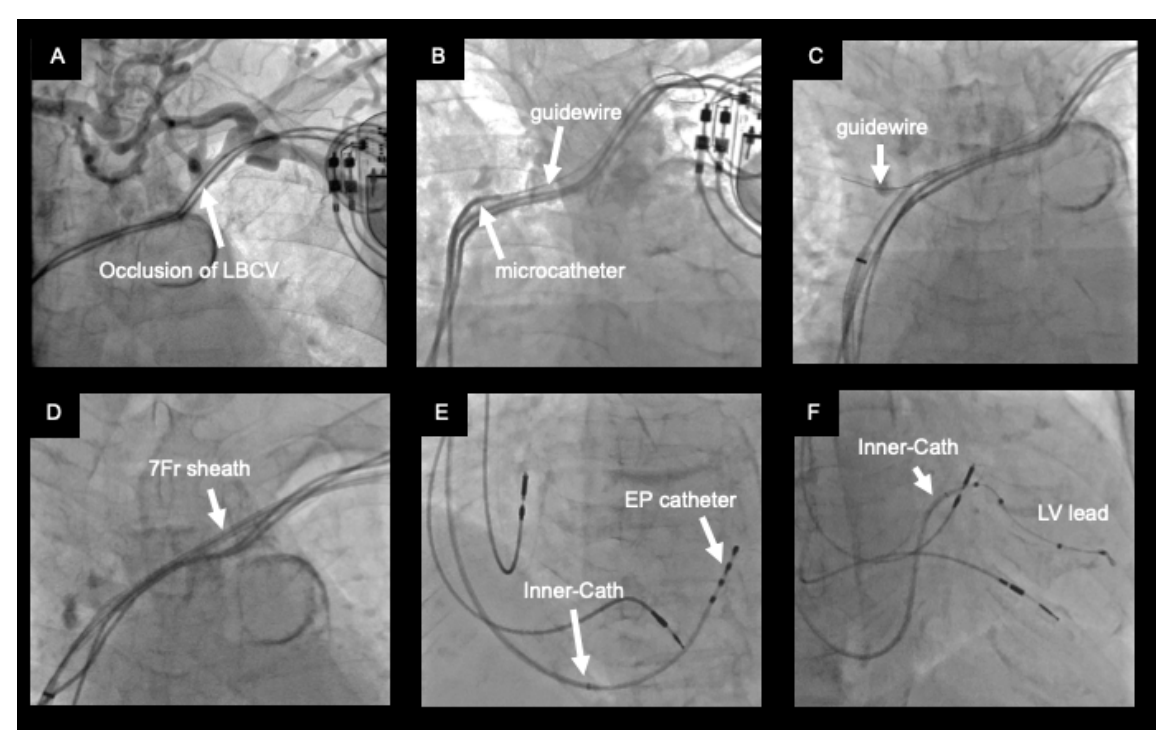

Table 1. Patient Characteristics

\begin{tabular}{llll}
\hline & Inner-Cath $\mathrm{N}=42$ & Outer-Cath $\mathrm{N}=32$ & $\mathrm{P}$ \\
\hline Age & $63 \pm 12$ & $72 \pm 11$ & 0.015 \\
male / female & $34 / 8$ & $23 / 9$ & 0.36 \\
BMI [kg/m2] & $21.9 \pm 4.2$ & $22.5 \pm 2.9$ & 0.48 \\
Ischemic /nonischemic & $13 / 29$ & $12 / 20$ & 0.35 \\
CM & & & \\
CRTD / CRTP & $40 / 2$ & $21 / 11$ & $<0.001$ \\
Non-paroxysmal AF & 9 & 9 & 0.51 \\
QRS duration [ms] & $141 \pm 4$ & $147 \pm 5$ & 0.31 \\
BNP [pg/ml] & $517 \pm 479$ & $665 \pm 668$ & 0.27 \\
Creatinine [mg/dl] & $1.6 \pm 1.7$ & $1.3 \pm 0.5$ & 0.32 \\
eGFR & $48.7 \pm 15.1$ & $46.3 \pm 18.9$ & 0.55 \\
[ml/min/1.73m2] & & & \\
LVEF[\%] & $28 \pm 7$ & $33 \pm 12$ & 0.17 \\
LVDd [mm] & $64 \pm 7$ & $63 \pm 9$ & 0.59 \\
LVDs [mm] & $56 \pm 7$ & $53 \pm 11$ & 0.21 \\
\hline
\end{tabular}

CM; cardiomyopathy, CRTD; cardiac resynchronization therapy defibrillator, CRTP; cardiac resynchronization therapy pacemaker, AF; atrial fibrillation, LVEF; left ventricular ejection fraction, LVDd; left ventricular diastolic diameter

Table 2. Procedure outcomes

\begin{tabular}{llll}
\hline & Inner-Cath $\mathrm{N}=42$ & Outer-Cath $\mathrm{N}=32$ & $\mathrm{P}$ \\
\hline $\begin{array}{l}\text { Success rate of LV lead } \\
\text { placement, }(\%)\end{array}$ & $42(100)$ & $30(93.8)$ & 0.10
\end{tabular}




\begin{tabular}{|c|c|c|c|}
\hline & Inner-Cath $\mathrm{N}=42$ & Outer-Cath $\mathrm{N}=32$ & $\mathrm{P}$ \\
\hline $\begin{array}{l}\text { Use of additional } \\
\text { catheter, }(\%)+\end{array}$ & $2(4.8)$ & $18(56.3)$ & $<0.001$ \\
\hline $\begin{array}{l}\text { Total procedure time } \\
\text { [min] }\end{array}$ & $148 \pm 38$ & $168 \pm 42$ & 0.024 \\
\hline $\begin{array}{l}\text { Time to LV lead } \\
\text { placement [min] }\end{array}$ & $77 \pm 35$ & $96 \pm 36$ & 0.011 \\
\hline Fluoroscopic time [min] & $39 \pm 20$ & $47 \pm 26$ & 0.10 \\
\hline $\begin{array}{l}\text { Fluoroscopic dose } \\
{[\mathrm{mGy}]}\end{array}$ & $343 \pm 290$ & $321 \pm 180$ & 0.71 \\
\hline Contrast dose $[\mathrm{ml}]$ & $43 \pm 27$ & $31 \pm 15$ & 0.12 \\
\hline $\begin{array}{l}\text { LV lead threshold [V, } \\
0.4 \mathrm{msec}]\end{array}$ & $0.9 \pm 0.5$ & $1.2 \pm 0.5$ & 0.049 \\
\hline $\begin{array}{l}\text { LV lead impedance } \\
\text { [ohm] }\end{array}$ & $597 \pm 195$ & $584 \pm 182$ & 0.79 \\
\hline $\begin{array}{l}\text { LV lead dislodgement } \\
\text { during peeling-off of } \\
\text { guiding sheaths, }(\%) \\
\text { Location of LV lead } \\
\text { placement, }(\%)\end{array}$ & $5(11.9)$ & $6(18.6)$ & 0.42 \\
\hline Antero-lateral & $14(33.3)$ & $4(12.9)$ & 0.11 \\
\hline Mid-lateral & $15(35.7)$ & $17(54.8)$ & \\
\hline Postero-lateral & $13(31.5)$ & $10(32.3)$ & \\
\hline
\end{tabular}

LV; left ventricular

+The additional use of an Outer-Cath in the Inner-Cath group or the additional use of an Inner-Cath in the Outer-Cath group.

Table 3. Procedure-related complications

\begin{tabular}{llll}
\hline & Inner-Cath group N=42 & Outer-Cath group N=32 & $\mathrm{P}$ \\
\hline $\begin{array}{l}\text { All complications, (\%) } \\
\begin{array}{l}\text { Mechanical CS injuries, } \\
\text { (\%) (Dissection / }\end{array}\end{array}$ & $0(0 / 0)$ & $10(31.3)$ & 0.002 \\
$\begin{array}{l}\text { perforation) } \\
\text { Lead dislodgement after } \\
\text { procedure LV leads / RV }\end{array}$ & $0 / 0 / 2$ & $5(15.6)(3 / 2)$ & 0.013 \\
$\begin{array}{l}\text { leads / Atrial leads } \\
\text { Hematoma }\end{array}$ & 0 & $1 / 1 / 2$ & 0.23 \\
\hline
\end{tabular}

CS; coronary sinus, LV left ventricular, RV; right ventricular

\section{References}

1. Abraham WT, Fisher WG, Smith AL, Delurgio DB, Leon AR, Loh E, Kocovic DZ, Packer M, Clavell AL, Hayes DL, Ellestad M, Trupp RJ, Underwood J, Pickering F, Truex C, McAtee P, Messenger J; MIRACLE Study Group. Multicenter InSync Randomized Clinical Evaluation. Cardiac resynchronization in chronic heart failure. N Engl J Med 2002;346:1845-53.

2. Bristow MR, Saxon LA, Boehmer J, Krueger S, Kass DA, De Marco T, Carson P, DiCarlo L, DeMets D, White BG, DeVries DW, Feldman AM; Comparison of Medical Therapy, Pacing, and Defibrillation 
in Heart Failure (COMPANION) Investigators. Cardiac-resynchronization therapy with or without an implantable defibrillator in advanced chronic heart failure. N Engl J Med 2004;350:2140-50.

3. Cleland JG, Daubert JC, Erdmann E, Freemantle N, Gras D, Kappenberger L, Tavazzi L; Cardiac Resynchronization-Heart Failure (CARE-HF) Study Investigators. The effect of cardiac resynchronization on morbidity and mortality in heart. N Engl J Med 2005;352:1539-49.

4. Moss AJ, Hall WJ, Cannom DS, Klein H, Brown MW, Daubert JP, Estes NA 3rd, Foster E, Greenberg H, Higgins SL, Pfeffer MA, Solomon SD, Wilber D, Zareba W; MADIT-CRT Trial Investigators. Cardiac-resynchronization therapy for the prevention of heart-failure events. N Engl J Med 2009;361:1329-1338.

5. Cleland JG, Daubert JC, Erdmann E, Freemantle N, Gras D, Kappenberger L, Tavazzi L. Longerterm effects of cardiac resynchronization therapy on mortality in heart failure [the CArdiac REsynchronization-Heart Failure (CARE-HF) trial extension phase]. Eur Heart J 2006; 27: 19281932.

6. Tang AS, Wells GA, Talajic M, Arnold MO, Sheldon R, Connolly S, Hohnloser SH, Nichol G, Birnie DH, Sapp JL, Yee R, Healey JS, Rouleau JL; Resynchronization-Defibrillation for Ambulatory Heart Failure Trial Investigators. Cardiac-resynchronization therapy for mild-to-moderate heart failure. N Engl J Med 2010;363:2385-2395.

7. Khazanie P, Greiner MA, Al-Khatib SM, Piccini JP, Turakhia MP, Varosy PD, Masoudi FA, Curtis LH, Hernandez AF; National Cardiovascular Data Registry. Comparative Effectiveness of Cardiac Resynchronization Therapy Among Patients With Heart Failure and Atrial Fibrillation: Findings From the National Cardiovascular Data Registry's Implantable Cardioverter-Defibrillator Registry. Circ Heart Fail. 2016 Jun;9(6):10.1161/CIRCHEARTFAILURE.115.002324 e002324.

8. Kalscheur MM, Saxon LA, Lee BK, Steinberg JS, Mei C, Buhr KA, DeMets DL, Bristow MR, Singh SN. Outcomes of cardiac resynchronization therapy in patients with intermittent atrial fibrillation or atrial flutter in the COMPANION trial. Heart Rhythm 2017;14:858-865.

9. Da Costa A, Gate-Martinet A, Rouffiange P, Cerisier A, Nadrouss A, Bisch L, Romeyer-Bouchard C, Isaaz K. Anatomical factors involved in difficult cardiac resynchronization therapy procedure: a non-invasive study using dual-source 64-multi-slice computed tomography. Europace. 2012;14:833-40.

10. Morgan JM, Delgado V. Lead positioning for cardiac resynchronization therapy: techniques and priorities. Europace 2009;11 Suppl 5:v22-8.

11. Er F, Yüksel D, Hellmich M, Gassanov N. Comparison of Conventional versus Steerable-Catheter Guided Coronary Sinus Lead Positioning in Patients Undergoing Cardiac Resynchronization Device Implantation. PLoS One. 2015;10:e0143292.

12. ackson KP, Hegland DD, Frazier-Mills C, Piccini JP, Koontz JI, Atwater BD, Daubert JP, Worley SJ. Impact of using a telescoping-support catheter system for left ventricular lead placement on implant success and procedure time of cardiac resynchronization therapy. Pacing Clin Electrophysiol 2013;36:553-8.

13. Friedman DJ, Jackson KP. How to Implant Cardiac Resynchronization Therapy in a Busy Clinical Practice. Card Electrophysiol Clin 2019;11:67-74.

14. León AR, Delurgio DB, Mera F. Practical approach to implanting left ventricular pacing leads for cardiac resynchronization. J Cardiovasc Eelctrophysiol 2005;16:100-5.

15. Auricchio A, Gasparini M, Linde C, Dobreanu D, Cano Ó, Sterlinski M, Bogale N, Stellbrink C, Refaat MM, Blomström-Lundqvist C, Lober C, Dickstein K, Normand C. Sex-Related Procedural Aspects and Complications in CRT Survey II: A Multicenter European Experience in 11,088 Patients. JACC Clin Electrophysiol 2019;5:1048-1058.

16. de Cock CC, van Campen CM, Visser CA. Major dissection of the coronary sinus and its tributaries during lead implantation for biventricular stimulation: angiographic follow-up. Europace 2004;6:43-7.

17. Ponikowski P, Voors AA, Anker SD, Bueno H, Cleland JGF, Coats AJS, Falk V, González-Juanatey JR, Harjola VP, Jankowska EA, Jessup M, Linde C, Nihoyannopoulos P, Parissis JT, Pieske B, Riley JP, Rosano GMC, Ruilope LM, Ruschitzka F, Rutten FH, van der Meer P; ESC Scientific Document Group. 2016 ESC Guidelines for the diagnosis and treatment of acute and chronic heart failure: The 
Task Force for the diagnosis and treatment of acute and chronic heart failure of the European Society of Cardiology (ESC)Developed with the special contribution of the Heart Failure Association (HFA) of the ESC. Eur Heart J 2016;37:2129-2200.

18. Bisch L, Da Costa A, Dauphinot V, Romeyer-Bouchard C, Khris L, M'baye A, Isaaz K. Predictive factors of difficult implantation procedure in cardiac resynchronization therapy. Europace 2010;12:11418.

19. Gamble JHP, Herring N, Ginks M, Rajappan K, Bashir Y, Betts TR. Procedural Success of Left Ventricular Lead Placement for Cardiac Resynchronization Therapy: A Meta-Analysis. JACC Clin Electrophysiol. 2016;2:69-77.

20. Hummel JD, Coppess MA, Osborn JS, Yee R, Fung JW, Augostini R, Li S, Hine D, Singh JP. RealWorld Assessment of Acute Left Ventricular Lead Implant Success and Complication Rates: Results from the Attain Success Clinical Trial. Pacing Clin Electrophysiol. 2016;39:1246-1253.

21. Bose A, Kandala J, Upadhyay GA, Riedl L, Ahmado I, Padmanabhan R, Gewirtz H, Mulligan LJ, Singh JP. Impact of myocardial viability and left ventricular lead location on clinical outcome in cardiac resynchronization therapy recipients with ischemic cardiomyopathy. J Cardiovasc Electrophysiol. 2014;25:507-513.

22. Worley SJ. Implant venoplasty: dilation of subclavian and coronary veins to facilitate device implantation: indications, frequency, methods, and complications. J Cardiovasc Electrophysiol 2008;19:1004-7.

23. Marcial JM, Worley SJ. Venous System Interventions for Device Implantation. Card Electrophysiol Clin 2018;10:163-177.

\section{Figure Legends}

\section{Figure 1. LV lead placement guided by Inner-Cath alone}

A: A 5Fr deflectable EP catheter was advanced to the CS to guide the Inner-Cath. B: Once the Inner-Cath was inserted in the CS trunk, CS venography was performed. In this and other figures, the white arrow indicates where the Inner-Cath ends. C: Finally, an LV lead was advanced to the target vein along an 0.014-inch guidewire. D: Example of occlusive CS venography performed with a balloon catheter placed via an Inner-Cath followed by LV lead placement.

CS; coronary sinus, LV; left ventricular.

\section{Figure 2. Representative cases with LV-LP guided by Inner-Cath alone}

LV leads placed in the posterolateral, lateral, and anterolateral branches of the coronary sinus. After InnerCath placement, venography was performed (upper panels) followed by LV lead placement (bottom panels). All LV lead placements were successfully guided by Inner-Cath alone in these patients. (white arrows indicate where the Inner-Cath ends)

\section{Figure 3. A case with CS perforation due to repeated CS cannulations with an Outer-Cath}

A: Although an LV lead was successfully placed with an Outer-Cath, it was repeatedly dislodged when peeling off the Outer-Cath. B: Leakage of contrast medium was observed in the pericardial space due to CS perforation caused by the repeated cannulations of the Outer-Cath into the CS. C,D: An LV lead placement was successfully guided by use of an Inner-Cath alone. (white arrows indicate where the Inner-Cath ends)

Figure 4. LV-LP guided by Inner-Cath alone after venoplasty in a case with occluded left brachiocephalic vein .

A: This patient's left brachiocephalic vein (LBCV) was completely occluded. B: An 0.014-inch guidewire was passed thorough the occluded LBCV with a retrograde approach using a microcatheter. C: Another 0.014-inch wire was passed through the LBCV with an anterograde approach after dilation of the occluded LBCV. D: A 7Fr sheath was inserted through the occluded LBCV. E: An Inner-Cath was advanced into the CS using a 5Fr EP catheter. F: LV lead placement was successfully guided by an Inner-Cath alone. 